\title{
'Unbearable suffering': a qualitative study on the perspectives of patients who request assistance in dying
}

\author{
Marianne K Dees, ${ }^{1}$ Myrra J Vernooij-Dassen, ${ }^{2}$ Wim J Dekkers, ${ }^{3}$ Kris C Vissers, ${ }^{4}$ \\ Chris van Weel ${ }^{1}$
}

${ }^{1}$ Department of Primary and Community Care, Radboud University Nijmegen Medical Centre, Nijmegen, The Netherlands

${ }^{2}$ Department of Primary and Community Care, Radboud University Nijmegen Medical Centre, Scientific Institute for Quality of Healthcare, The Netherlands

${ }^{3}$ Radboud University Nijmegen Medical Centre, Section of Ethics, Philosophy and History of Medicine, Scientific Institute for Quality of Healthcare, The Netherlands

${ }^{4}$ Department of Anesthesiology, Pain and Palliative Medicine, Radboud University Nijmegen Medical Centre, The Netherlands

\section{Correspondence to}

Marianne K Dees, General Practitioner, Radboud University Nijmegen Medical Centre, Department of Primary and Community Care, Internal postal code 117, P0 Box 9101, 6500 HB Nijmegen, The Netherlands; m.dees@elg.umcn.nl

Received 17 May 2011 Accepted 4 July 2011

\begin{abstract}
Background One of the objectives of medicine is to relieve patients' suffering. As a consequence, it is important to understand patients' perspectives of suffering and their ability to cope. However, there is poor insight into what determines their suffering and their ability to bear it.

Purpose To explore the constituent elements of suffering of patients who explicitly request euthanasia or physicianassisted suicide (EAS) and to better understand unbearable suffering from the patients' perspective.

Patients and methods $A$ qualitative study using indepth face-to-face interviews was conducted with 31 patients who had requested EAS. The grounded theory approach was used to analyse the data.

Results Medical, psycho-emotional, socio-environmental and existential themes contributed to suffering. Especially fatigue, pain, decline, negative feelings, loss of self, fear of future suffering, dependency, loss of autonomy, being worn out, being a burden, loneliness, loss of all that makes life worth living, hopelessness, pointlessness and being tired of living were constituent elements of unbearable suffering. Only patients with a psychiatric (co) diagnosis suffered unbearably all the time.

Conclusions Unbearable suffering is the outcome of an intensive process that originates in the symptoms of illness and/or ageing. According to patients, hopelessness is an essential element of unbearable suffering. Medical and social elements may cause suffering, but especially when accompanied by psycho-emotional and existential problems suffering will become 'unbearable'. Personality characteristics and biographical aspects greatly influence the burden of suffering. Unbearable suffering can only be understood in the continuum of the patients' perspectives of the past, the present and expectations of the future.
\end{abstract}

\section{INTRODUCTION}

The main objectives of medicine are to relieve patients' suffering and cure their illness. ${ }^{1}$ Once patients can no longer be cured, palliative care is employed to improve the quality of life by prevention and relief of suffering. ${ }^{2}$ The availability of palliative care has increased in the past decades. ${ }^{3} 4$ Nevertheless 1 in 10 palliative care patients have asked, at some point, a specific question about assistance in dying to alleviate suffering. ${ }^{5-7}$ In states and countries where euthanasia or physicianassisted suicide (EAS) has been legalised-Oregon, Washington State, Montana, Switzerland, Belgium, Luxembourg and the Netherlands-unbearable suffering is a major consideration in the professional assessment of a request for EAS. ${ }^{6-10}$ In an integrative literature review we established that unbearable suffering in the context of a request for EAS has a medical, a psychological, a social and an existential dimension. ${ }^{11}$ It also made it obvious that despite its essential place in end-of-life decision-making, there is no generally accepted definition of 'unbearable suffering' and there is a lack of knowledge of patients' perceptions of 'unbearable suffering'. ${ }^{11}$ In the Netherlands, patients who explicitly request EAS are expected to describe their situation in terms of a lack of hope and an inability to cope with their suffering. This provides a unique opportunity to study unbearable suffering from the patient's perspective. Qualitative research using in-depth interview techniques is best suited to uncover unbearable suffering from the patients' perspectives. Understanding 'suffering' and knowledge of its constituent elements provides a tool that might contribute to an early detection and a proactive approach to prevent suffering becoming unbearable.

We conducted a study to explore what patients who had explicitly requested EAS considered 'suffering' to entail and what made their suffering 'unbearable'.

\section{METHODS}

\section{Study design}

We used a design of qualitative, in-depth, face-toface interviews. ${ }^{12} 13$ Purposeful sampling was used to ensure diversity in diagnosis.

\section{Recruitment and patient selection}

With the assistance of the Support and Consultation on Euthanasia in the Netherlands (SCEN) network, we recruited patients who had explicitly requested EAS. We also approached a hospice, a hospital and a nursing home and placed a notice in the journal Right to die-NL. To ensure diversity in the sampling of perceived suffering, we included both patients whose EAS requests had been granted and denied. The treating physician was asked to inform the patient about the study. The interviewer contacted the patient by telephone and written information was sent by mail. Patients who reacted to the notice could directly contact the interviewer by phone. All patients signed an informed consent form.

\section{Interviews}

The interviews took place at the patients' residences and lasted 30-120 min. Patients were interviewed alone to ensure that the caregiver's 
presence did not influence the information they gave. We developed an interview guide (box 1) on the basis of the research question and a literature review. ${ }^{11}$ Each interview started with a question about the development of the request. Subsequently constituent elements of suffering were explored. All patients were asked about their ability to enjoy things. Finally each patient was asked what made suffering unbearable. The interviewer (MKD), a family physician and SCEN specialist, closely followed the interview line brought forward by the patient. ${ }^{14}$ The interviews were audio-taped and transcribed verbatim. Demographics were collected before the interviews and the medical records and SCEN reports were retrieved afterwards.

\section{Definitions}

In accordance with the Dutch law, euthanasia was defined as the termination of life on the explicit request of the patient by a physician with the intention to end hopeless and unbearable suffering. Physician-assisted suicide was defined as assisting in the suicide of a patient by a physician. A request for EAS is called 'explicit' when the patient has specifically asked the physician to (help) end the patient's life.

\section{Qualitative data analysis}

We used the constant comparative method to analyse the data. ${ }^{15}$ This method is part of the grounded theory approach in which concepts emerge as theory is formed. We used ATLAS.ti version 5.5 software to process the data. Analysis started as soon as the first data were collected and continued with each additional interview. The first step in the analysis was data reduction; two researchers (MKD and a psychologist) coded the transcript independently to minimise subjectivity. Coding is the interpretive process in which we give conceptual labels to the data. The purpose is to attain new insights by breaking through standard ways of thinking about phenomena reflected in the data. ${ }^{15}$ The sequence was as follows: we used codes that were closely related to the text fragments. After five interviews, we compared the analysts' codes and three researchers (MKD, a psychologist and MJV) discussed them until they reached consensus. Then a new coding scheme was developed for further use. New codes could be added. When no more new codes about suffering appeared, we were satisfied that saturation had been reached. We grouped codes referring to the same phenomenon in categories and categories in themes. MKD analysed all transcripts again to come to an understanding of how the different elements of suffering contributed in individual cases to unbearable suffering. Finally, a grounded theory approach was used to derive hypotheses about unbearable suffering from the data. Five researchers reached consensus about the codes, categories and themes in peer-group discussion. This group included two family doctors (CW and $\mathrm{MKD}$ ), one of whom has experience with EAS $(\mathrm{MKD})$, a sociologist experienced in qualitative end-of-life research (MLV), an ethicist (WJD) and a palliative care specialist $(\mathrm{KV})$. They used an iterative procedure and re-reading to facilitate the discussion.

\section{Box 1 Interview guide}

- How did your request for euthanasia or physician-assisted suicide develop?

- What made your request topical?

- What is your suffering made up of?

- What makes your suffering unbearable?

\section{RESULTS}

Between April 2008 and July 200945 patients were prepared for interviewing. Twelve were excluded after interviewing because they had not made an explicit request. Two patients died before their interviews could take place. Altogether, 31 patients were included in the study. When data from the last seven interviews were entered, no new codes emerged and we concluded that saturation had been reached.

\section{Patient characteristics}

The participants varied in gender, age, marital status, educational level and residence. They came from rural and urban areas all over the Netherlands. Except those with a psychiatric diagnosis, these patients showed a high degree of self-realisation in social, occupational and economic status. Five patients considered themselves religious. The requests of 11 patients were not granted. In eight cases, this refusal was directly related to the absence of a physical diagnosis (four patients had psychiatric diseases and four patients were tired of living). Two refusals were related to the institutional policies of the places of residence. These patients died as a result of non-treatment of pneumonia and palliative sedation. The request of one patient with cancer was refused because of the coexistence of a depression. He refused treatment and stopped eating and drinking. The request of a second patient with cancer was postponed by successful treatment of her depression. According to the medical records and the reports of SCEN consultants all patients were clinically assessed on depression. The life expectancy of the patients with cancer, at the moment EAS was performed, varied from 2 to 120 days with a mean of 34 days (table 1 ).

\section{The patients' perspectives on suffering}

The patients described suffering in a multiplicity of very individual ways (table 2). The coding of their statements resulted in 21 categories from which, in accordance with our literature review ${ }^{11}$ four themes emerged: medical, psycho-emotional, socio-environmental and existential (table 3).

\section{The medical context}

Suffering always originated in symptoms of illness or ageing. Within the medical theme five categories could be distinguished: physical, cognitive and psychiatric symptoms, side effects of medical treatment and decline.

The physical symptoms varied greatly, depending on the specific course of the illness or ageing. Of the physical symptoms general symptoms such as fatigue, pain, feeling miserable increased suffering more than tract-related symptoms. Decline 2 was often mentioned as an important reason for suffering. Cognitive symptoms caused much suffering. Patients with psychiatric symptoms emphasised the burden of their suffering. The side effects of medical treatment for psychiatric conditions and cancer were named as an additional cause for suffering.

\section{The psycho-emotional context}

The six subcategories in the psycho-emotional theme were loss of self, negative feelings, fear of future suffering, dependency, loss of autonomy and mental exhaustion. With the exception of patients with a psychiatric diagnosis, the patients described themselves as autonomous persons aiming to be significant to others, in favour of communicating with others, preferring an active lifestyle. Loss of self was a great cause of suffering (table 2). Some patients expressed the presence of negative feelings that took centre stage in their minds and thus added to their suffering. The patients mentioned a wide range of fears of 


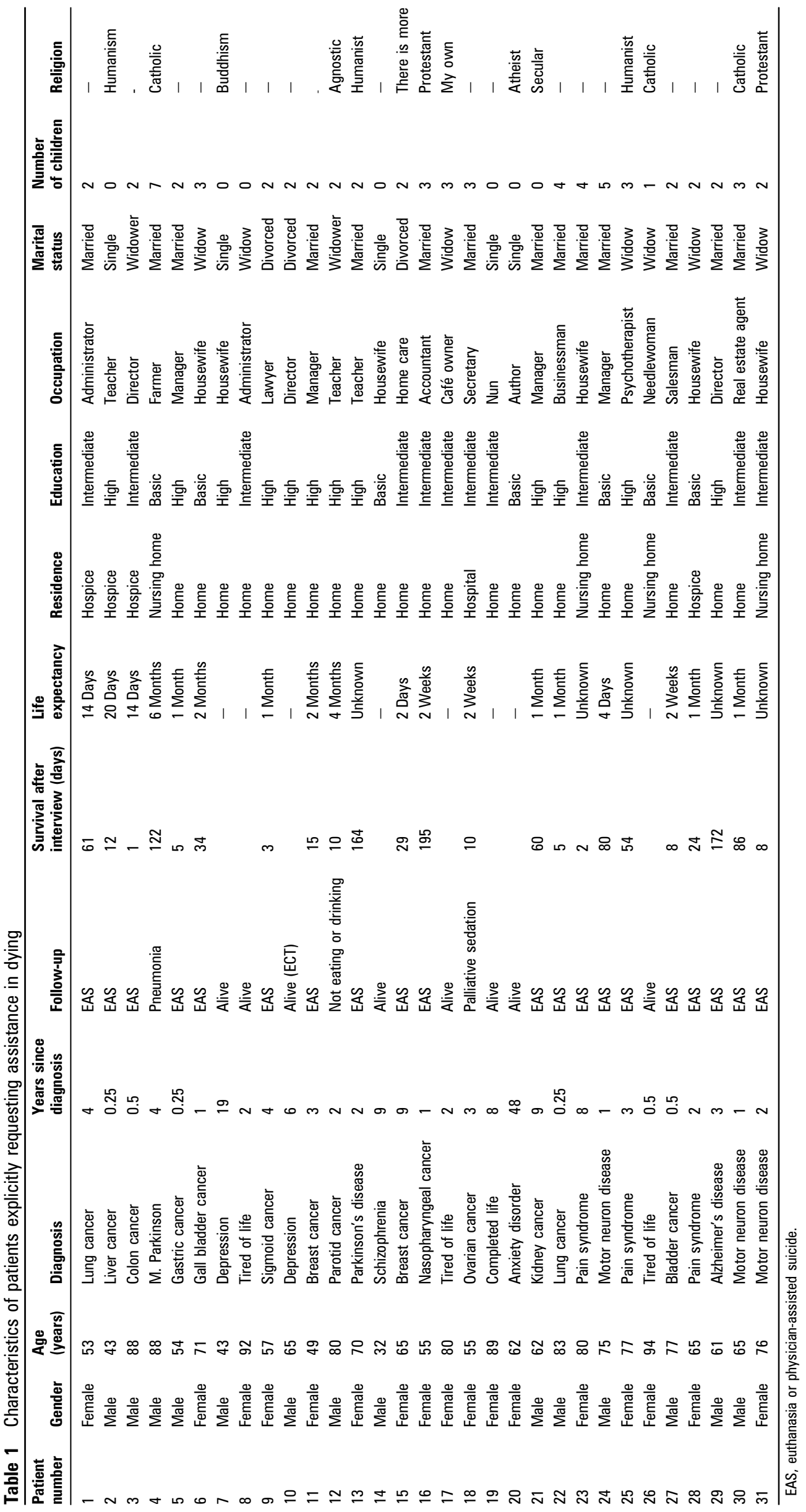


Table 2 Remarks about unbearable suffering made by patients who explicitly requested assistance in dying

\begin{tabular}{|c|c|c|c|}
\hline & Theme & Patient & Remarks \\
\hline 1. & Medical & & \\
\hline $1.1 \mathrm{a}$ & $\begin{array}{l}\text { Illness-related physical } \\
\text { symptoms }\end{array}$ & 31 & I have fecal incontinence. I can no longer swallow and in hot weather I really envy people who can drink \\
\hline $1.1 \mathrm{c}$ & Pain & 28 & $\begin{array}{l}\text { I am in pain all the time, I am in pain at night, I wake up with pain and I go to bed with pain. If they could take away half } \\
\text { my pain I wouldn't be thinking about euthanasia }\end{array}$ \\
\hline 1.3 & Psychiatric symptoms & 7 & $\begin{array}{l}\text { I suffer so much that I can't recall when life was lovely and happy. My life is hell. My life is inhuman. I have such deep } \\
\text { pain inside }\end{array}$ \\
\hline 1.4 & $\begin{array}{l}\text { Misery due to medical } \\
\text { treatment }\end{array}$ & 11 & $\begin{array}{l}\text { I was simply nauseous and my energy was just running out. And I said that I wished that, just for a short period of time, } \\
\text { I could eat normally and not have to fight to keep it down and that I wanted to have a little more energy. Then I } \\
\text { stopped the chemo and indeed I had that improvement }\end{array}$ \\
\hline 1.5 & Decline & 29 & I can no longer bear the undermining nature of my disease; there are moments when I can't find a single word in my brain \\
\hline 2.3 & Fear of future suffering & 21 & $\begin{array}{l}\text { Finally the illness that dominates everything will wipe out all life has to offer me, what I feared most is exactly what will } \\
\text { happen to me. I won't belong anymore, the emptiness of existence, the lack of independence, being unable to do things } \\
\text { myself, being at the mercy of others whom I will have to beg to do the things I need in a way that's suitable for me }\end{array}$ \\
\hline 2.4 & Dependency & 26 & I can't do anything anymore, they leave me lying here until 10 o'clock and they only wash me when they feel like it \\
\hline 2.5 & Autonomy & 27 & $\begin{array}{l}\text { I say: I have made my decision. I don't want you to treat me any longer. Someone says, now you are probably too weak } \\
\text { for chemo. I say: if I'm not too weak and they want to give me chemo, I will refuse it, because in the little time that is } \\
\text { left to me I want quality of life, not quantity of life. I decided that year ago: if this were to overcome me, then that's what } \\
\text { I would choose }\end{array}$ \\
\hline 2.6 & Mental exhaustion & 2 & Mentally I am completely exhausted. I can't fight it anymore. \\
\hline 3. & Socio-environmental & & \\
\hline 3.1 & $\begin{array}{l}\text { Loss of being socially } \\
\text { significant }\end{array}$ & 3 & $\begin{array}{l}\text { I was a very handy man: there were all kinds of odd jobs to be done in the home for the elderly and I enjoyed doing } \\
\text { them. Then I felt useful to this society. I can't do it anymore, I can't do anything anymore, but I lived a worthy life... }\end{array}$ \\
\hline 3.5 & Loneliness & 8 & $\begin{array}{l}\text { The home help comes once a month. Even though I look healthy, I have so much grief because I have lost everybody, } \\
\text { your parents, your husband and your sisters and my brother was shot dead by the Germans. Everything is gone }\end{array}$ \\
\hline 3.6 & Biography & 10 & $\begin{array}{l}\text {...claustrophobia of my existence. To put it simply, it is insight without perspective. Never in my life have } \\
\text { I felt any love. If there had been some warmth and love and safety, I could have grown }\end{array}$ \\
\hline 4. & Existential & & \\
\hline 4.1 & Limitation of activities & 25 & $\begin{array}{l}\text { I can't drive anymore. I loved to paint and draw, but I can't do that either anymore. Everything I enjoyed is gone. } \\
\text { And then, my sight became worse... }\end{array}$ \\
\hline 4.2 & Hopelessness & 16 & You lie in bed and none of the normal functions come back. They will never come back and it will only get worse \\
\hline 4.3 & Pointlessness & 5 & $\begin{array}{l}\text { I'm not interested at all anymore, I just lie here and what's the point? There isn't any. I no longer read. Not books, } \\
\text { not newspapers. I have CDs and the Walkman right here. Well, I've listened to, um, two CDs and that's enough. } \\
\text { And yet I really loved music, but it's all over. I'm just not interested anymore }\end{array}$ \\
\hline 4.4 & Being tired of life & 19 & I think that my life is absolutely completed. I don't know what else I could want \\
\hline
\end{tabular}

future suffering. These fears were related to the course of illnesses, physical symptoms, the process of dying, decline, loss of self-determination or anxiety. Sometimes loss of autonomy was experienced as a threat to personality. Being treated as a patient especially when others had to take over everyday tasks or when being bedridden was described as suffering. The wish to have a say about their death was another expression of the desire for autonomy. Many patients suffered from mental exhaustion.

\section{The socio-environmental context}

The six subcategories in the socio-environmental theme were loss of social significance, communicative problems, discontent with residential circumstances and quality of care, being a burden, loneliness and biographical aspects. The patients mentioned loss of social significance often. Exclusively patients with motor neuron disease or dementia mentioned communication problems, but such problems were of minor importance compared with other symptoms of these diseases. A prospect of a possible transfer to a nursing home added to suffering.

Patients who had high-quality informal care and strong family connections and who had been the central figures in their families were particularly concerned about being a burden.

Those who were widowed, patients with psychiatric problems and patients forced to live separately from their partners 
Table 3 Themes, categories and codes of suffering named by patients explicitly requesting assistance in dying

\begin{tabular}{lll}
\hline Themes & Categories & Codes \\
\hline Medical & Physical symptoms & $\begin{array}{l}\text { General symptoms: pain, fatigue, general malaise, feeling miserable, physical deterioration, changed } \\
\text { appearance }\end{array}$
\end{tabular}
appearance

Gastrointestinal symptoms: eating and drinking problems, anorexia, nausea, vomiting, loss of weight, defecation problems

Nervous and locomotor symptoms: deterioration of locomotor function, mobility and coordination; loss of balance; dizziness

Dyspnoea

Cognitive symptoms

Psychiatric symptoms

Effects of medical treatment

Decline

Psycho-emotional Loss of self

Negative feelings Fears of future suffering

Dependency Loss of autonomy

Being worn out

Socio-environmental Loss of social significance Communicative problems Discontent about residential circumstances and quality of care

Being a burden

Loneliness

Biographical aspects

Existential

Loss of important and pleasurable activities

Hopelessness

Pointlessness

Life is over
Incontinence

Confrontations with cognitive deterioration, deterioration of ready knowledge, inability to concentrate, inability to participate in conversations, slow-wittedness, loss of memory

Loss of emotional control, loss of emotions, insomnia, de-realisation, depersonalisation, suicidal ideation, depression, identity crisis, fear, addiction

Side effects of chemotherapy, radiotherapy, psycho-pharmaceuticals and morphine. Complications of operations

Physical, cognitive and emotional

Loss of the following:

- Autonomy: independence and being in control Expression of personal traits: social-mindedness readiness to help others, being of significance, caring, pride in achievements

- Communication style: considerate of the views of others, open

- Specific personality descriptors: modest, honest, loyal, consistent, interested, rational, humorous, relativistic, optimistic, uncomplaining, not overly emotional

- Favourite activities: active outdoor events and 'enjoying life'-for example, going out for dinner, etc Impotence, bitterness, misery, emptiness, suffering, emotional pain, disappointment, sadness

The course of the illness and dying: getting worse, uncontrollable symptoms, a horrible death Cognitive decline: deterioration, loss of control of the mind, loss of community, becoming insane with fear, being unable to recognise surroundings

Consequences of palliation: side effects of treatment, including morphine

Physical decline: deterioration, dullness, urinary incontinence, mechanical ventilation

Physical symptoms: nausea, pain, choking, dyspnoea

Loss of self-determination: being totally unable to do anything, loss of control, vegetative state, being bedridden.

Emotional aspects: suffering, anxiety

Being dependent, loss of physical functions of everyday living, being bedridden

The way others treat you: patient role, being treated as a hothouse plant, not being seen as a human being, being pressured to make decisions

Loss of self-determination: loss of direction, loss of making your own decisions, loss of independence, impaired daily functioning

Desire to control death: not wanting to experience the end stage of the disease, not wanting to suffer to the end, desire to have a say about your own dying, wanting your preferred way of dying, wanting to die with dignity, wanting no prolonged dying, desire to die at home, wishing to have some influence on the memories left behind

Not being able to stand it anymore, demoralisation, being so tired, exhausted by the treatments, tired of fighting the illness

Not being significant for society or loved ones, Loss of social, occupational and family roles, status Inability to participate in conversation, inability to communicate

Residential: being unable to go home, nursing home as a prospect, unsuitable living conditions Quality of care: poor quality of professional care, disappointment in informal care

Being a psychological or physical burden to the next of kin and the formal and informal caregivers Loss of loved ones, withdrawal, isolation, being left alone

Family history, occupational history, autobiography, social background, bad marriage, sexual abuse, family trauma (eg, war)

Being unable to participate

Absence of any hope of improvement, absence or degrading future prospects, nature and progress of the disease, unsuccessful suicide attempts

Loss of joie de vivre, loss of purpose in life, loss of the will to live

Being tired of life or weary of living, a feeling that your life is completed were lonely. Aspects of the patients' past, such as sexual abuse, a bad marriage, or childhood in a war camp had a very individual influence on their suffering.

\section{The existential context}

All patients experienced existential suffering. There were four categories within this theme: loss of important and pleasurable activities, hopelessness, pointlessness and being tired of life. Loss of important and pleasurable activities comprised a long list of activities, which included managing the household, looking after the grandchildren, gardening, going out for dinner, companionship, reading, playing tennis, travelling abroad, listening to music and singing in a choir, being significant to others and having a wonderful job. All patients mentioned hopelessness. Hopelessness inevitably gave rise to feelings of pointlessness that resulted in being tired of life. 


\section{The patients' perspectives on unbearable suffering}

Patients who, in contrast with the other patients, emphasised continuous feelings of unbearable suffering, saying it was impossible "to be unable to enjoy anything anymore", had a psychiatric diagnosis. Subcategories of existential and psychoemotional themes contributed greatly to the perception of suffering becoming unbearable (table 4). As an 80-year-old man, a former mathematics teacher and musician put it: "I can't do anything anymore, I used to play music, participated in various clubs, all so very companionable, I had to say farewell to all of it. It feels so awful just waiting to become bedridden and then waiting to die". All patients considered hopelessness to be a main factor in the perception of unbearableness. This is illustrated by a 55 -year-old woman with nasopharyngeal cancer: "You lie on a bed and none of the normal functions come back. They will never come back and it will only get worse".

In addition, patients placed unbearable suffering in the broader context of their personality characteristics. They explained how the irreversible consequences of disease or ageing resulted in loss of self, loss of autonomy and mental exhaustion until they felt themselves no longer the persons they used to be. This is exemplified by a 53-year-old woman with lung cancer: "I lost my dignity, lying in bed in diapers, I am no longer the independent person I used to be". In the medical theme, untreatable neurological pain, fatigue, decline and particularly psychiatric symptoms made the suffering unbearable. A 65-yearold woman with neuropathic pain, on maximum analgesic treatment, expressed this as: "I am in pain all the time, I am in pain at night, I wake up with pain and I go to bed with pain. If they could only take away half my pain I wouldn't be thinking about euthanasia". In the socio-environmental theme, loneliness and being a burden often contributed to unbearable suffering, but these elements mostly were of minor importance.

Most patients, when asked about unbearable suffering, made up a balance of their past, their present and their expectations of the future. When this balance gave rise to feelings of hopelessness (often combined with feelings of pointlessness and being tired of life), they considered their suffering unbearable. As a 48-year-old woman putted it: "It is such an aggressive form of cancer. I saw all my energy going down the drain-what I could still do last week I can't do at all now. I really enjoyed my life, but now I have just to wait and see how things go and what death will look like". This was in great contrast with one 94-year-old woman, who was in excellent psycho-emotional condition and had no classifiable disease. She was living in a caring environment, communicating in a lively way and e-mailing with her extensive international network. She requested assistance in dying for reasons of being ready to quit life without any suffering at all

Table 4. Occurrence in themes and subcategories of unbearable suffering among patients

\begin{tabular}{|c|c|c|c|c|c|}
\hline Theme & $n^{*}$ & Subcategory & $n$ & Code & $n$ \\
\hline \multirow[t]{14}{*}{ Medical } & 29 & Physical symptoms & 29 & Fatigue & 10 \\
\hline & & & & Pain & 6 \\
\hline & & & & Feeling miserable & 1 \\
\hline & & & & Nausea & 1 \\
\hline & & & & Vomiting & 1 \\
\hline & & & & Eating or drinking problems & 4 \\
\hline & & & & Dyspnea & 3 \\
\hline & & & & Locomotor function & 5 \\
\hline & & & & Incontinence & 2 \\
\hline & & Psychiatric symptoms & 5 & & \\
\hline & & Complications of treatment & 6 & & \\
\hline & & Decline & 20 & Physical & 13 \\
\hline & & & & Cognitive & 10 \\
\hline & & & & Emotional & 1 \\
\hline \multirow[t]{7}{*}{ Psycho-emotional } & 29 & Loss of self & 17 & & \\
\hline & & Negative emotions & 17 & & \\
\hline & & Biographical aspects & 1 & & \\
\hline & & Fear of future suffering & 5 & & \\
\hline & & Dependency & 12 & & \\
\hline & & Loss of autonomy & 18 & & \\
\hline & & Being worn out & 16 & & \\
\hline \multirow[t]{5}{*}{ Socio-environmental } & 20 & Loss of social significance & 1 & & \\
\hline & & Communication problems & 3 & & \\
\hline & & $\begin{array}{l}\text { Discontent with residential } \\
\text { situation or quality of care }\end{array}$ & 5 & & \\
\hline & & Being a burden & 13 & & \\
\hline & & Loneliness & 8 & & \\
\hline \multirow[t]{4}{*}{ Existential } & 31 & Hopelessness & 30 & & \\
\hline & & Limitation of activities & 23 & & \\
\hline & & Pointlessness & 17 & & \\
\hline & & Tired of life & 17 & & \\
\hline
\end{tabular}




\section{DISCUSSION}

This study has brought to light the fact that unbearable suffering, from the perspective of patients who explicitly request EAS, is the outcome of an intensive process that originates in the symptoms of illness or ageing. The same elements from the medical, psychoemotional, socio-environmental and existential themes, as we identified earlier in a literature review, ${ }^{11}$ appeared to cause suffering. Especially elements from the existential and psychoemotional themes contributed to unbearable suffering and hopelessness was at the centre. Patients considered physical suffering less important, as earlier studies also demonstrate. ${ }^{13}$ 16-22 This may suggest that physical suffering had been palliated before the experience of unbearable suffering and the request for EAS came about. It became evident that uncontrollable physical symptoms, such as fatigue and neurological pain, contributed considerably to unbearable suffering through its negative effects on the motivations for living. For most patients who request EAS, time is limited; this affects the possible treatment of elements of unbearable suffering. It strengthens the importance of an early detection and treatment of symptoms like negative feelings, fears of future suffering, being worn out, loss of autonomy, loss of social significance, loss of activities, pointlessness and being tired of life to prevent suffering becoming unbearable.

Our study made obvious that the patient's request for EAS does not exclusively originate in feelings of unbearable suffering. In agreement with earlier findings, most patients did not experience unbearable suffering continuously. ${ }^{13}$ In addition, we found that patients who emphasised continuous feelings of unbearable suffering were diagnosed with a depression. Patients without a depression held the opinion that they were in an unbearable situation and named reasons to ask for assistance in dying in terms of unbearable suffering. Earlier research showed that a depressed mood is associated with a four times higher risk of a request for EAS. ${ }^{23}$ This underlines the importance of ruling out a depression before agreeing to a request. In agreement with earlier studies, physicians were unwilling to cooperate in requests with psychiatric (co)diagnosis. ${ }^{24} 25$

We found that patients evaluated their suffering in the context of personality characteristics, life history and existential motivations. The moment this evaluation evoked strong feelings of hopelessness, they perceived their suffering as unbearable. This progression of suffering to the point of hopelessness is compatible with a theoretical model of unbearable suffering, ${ }^{26}$ which implies that the outcome of unbearable suffering can only be fully understood from the individual patient's perspective and not so much from the burden of physical signs and symptoms. Individual patients emphasised the loss of all that life made worth living, felt that they were no longer the persons they used to be-Cassell's disintegration of the person ${ }^{1}$ - and had no hope of improvement.

Our study underlines that it is possible to carry out research with patients in end-of-life situations. Researchers and practitioners have long been concerned about burdening vulnerable patients in the last phase of their lives with research. Only in the past decade has such research become acceptable. ${ }^{27}{ }^{28}$ We found physicians prepared to ask terminally ill patients to participate in research. Patients found it useful to know that others would benefit from their experiences.

The study has some limitations. The findings should be placed in the context that unbearable suffering is among the criteria of lawful EAS in the Netherlands. Consequently, patients might feel urged to express the reasons for their request in terms of 'unbearable suffering'. It is unclear how this legal aspect affects the patients' phrasing of their request. It is unknown whether the participating physicians selected patients in view of specific elements of suffering or unbearable suffering. We do not know what kind of patients refused participation and whether refusal was related to the nature of suffering.

We hypothesise that, while suffering is rooted in the symptoms of illness or ageing, the existential and psycho-emotional themes determine how much hope there is and whether the patient is able to bear the suffering. Unbearable suffering can only be understood in the continuum of the patient's perspectives on the past, the present and expectations of the future. Without hopelessness, there is no perception of unbearable suffering.

These findings have implications well beyond decisions about EAS. Physicians, nurses and other healthcare professionals who practice palliative care should be able to understand patients' existential and psycho-emotional suffering (including the hopelessness) in an early stage to prevent suffering from becoming unbearable.

Acknowledgements The authors thank all the patients and physicians who participated in this study and Lieve Roets (LR) for her help in analysing the data.

Funding This study was supported by the Dutch Cancer Society (grant number KUN2007-03736).

\section{Competing interests None.}

Ethics approval The study was approved by the Research Ethics Committee at the Radboud University Nijmegen Medical Centre.

Provenance and peer review Not commissioned; externally peer reviewed.

\section{REFERENCES}

1. Cassell EJ. The nature of suffering and the goals of medicine. $N$ Engl J Med 1982:306:639-45.

2. World Health Organization. http://www.who.int/cancer/palliative/definition.

3. van den Block $\mathbf{L}$, Deschepper R, Bilsen J, et al. Euthanasia and other end of life decisions and care provided in final three months of life: nationwide retrospective study in Belgium. BMJ 2009;339:b2772

4. Centeno C, Clark D, Lynch T, et al. Facts and indicators on palliative care development in 52 countries of the WHO European region: results of an EAPC Task Force. Palliat Med 2007;21:463-71.

5. van der Heide A, Deliens L, Faisst $K$, et al. [End-of-life decision making in six European countries]. Ugeskr Laeger 2004;166:156-9.

6. Oregon Department of Human. Ninth Annual Report on Oregon's Death with Dignity Act. 2007.

7. Onwuteaka-Philipsen BD, Rurup ML, Pasman HR, et al. The last phase of life: who requests and who receives euthanasia or physician-assisted suicide? Med Care 2010;48:596-603.

8. Hudson PL, Kristjanson LJ, Ashby M, et al. Desire for hastened death in patients with advanced disease and the evidence base of clinical guidelines: a systematic review. Palliat Med 2006;20:693-701.

9. Smets T, Bilsen J, Cohen J, et al. Legal euthanasia in Belgium: characteristics of all reported euthanasia cases. Med Care 2010:48:187-92.

10. van Tol D, Rietjens J, van der Heide A. Judgment of unbearable suffering and willingness to grant a euthanasia request by Dutch general practitioners. Health Policy 2010;97:166-72.

11. Dees $\mathbf{M}$, Vernooij-Dassen M, Dekkers W, et al. Unbearable suffering of patients with a request for euthanasia or physician-assisted suicide: an integrative review. Psychooncology 2010;19:339-52.

12. Britten N. Qualitative interviews in medical research. BMJ 1995;311:251-3.

13. Pasman HR, Rurup ML, Willems DL, et al. Concept of unbearable suffering in context of ungranted requests for euthanasia: qualitative interviews with patients and physicians. BMJ 2009;339:b4362.

14. Stiel S, Pestinger M, Moser A, et al. The use of grounded theory in palliative care. Methodological Challenges and Strategies. J Palliat Med 2010;13:997-1003

15. Corbin J, Strauss A. Grounded theory research. Procedures, canons and evaluative criteria. Qual Soc 1990;13:S1-S21.

16. Coyle N, Sculco L. Expressed desire for hastened death in a select group of people living with advanced cancer: a phenomenological inquiry. Oncol Nurs Forum 2004; 13:699-709.

17. de Burlet HM, Hazenberg MJ. ['Tired of life': a reason to evaluate physical handicaps]. Ned Tijdschr Geneeskd 2003;147:633-5.

18. Ganzini L, Goy ER, Dobscha SK. Oregonians' reasons for requesting physician aid in dying. Arch Intern Med 2009;169:489-92. 
19. Mak YY, Elwyn G. Voices of the terminally ill. uncovering the meaning of desire for euthanasia. Palliat Med 2005;19:343-50.

20. Norwood F, Kimsma G, Battin MP. Vulnerability and the 'slippery slope' at the endof-life: a qualitative study of euthanasia, general practice and home death in The Netherlands. Fam Pract 2009;26:472-80.

21. Pearlman RA, Hsu C, Starks $\mathrm{H}$, et al. Motivations for physician-assisted suicide. J Gen Intern Med 2005;20:234-9.

22. Wilson KG. Desire for euthanasia or physician-assisted suicide in palliative cancer care. Health Psychol 2007;26:314-23.

23. van der Lee ML, van der Bom JG, Swarte NB, et al. Euthanasia and depression: a prospective cohort study among terminally ill cancer patients. J Clin Oncol 2005;20:6607-12.
24. Groenewoud $\mathbf{J H}$, Van der Maas PJ, van der WG, et al. Physician-assisted death in psychiatric practice in the Netherlands. N Engl J Med 1997;336:1795-801

25. Rurup ML, Muller MT, Onwuteaka-Philipsen BD, et al. Requests for euthanasia or physician-assisted suicide from older persons who do not have a severe disease: an interview study. Psychol Med 2005;35:665-71.

26. Rehnsfeldt A, Eriksson K. The progression of suffering implies alleviated suffering Scand J Caring Sci 2004;18:264-72.

27. Chochinov HM: The culture of research in palliative care. You probably think this song is about you. J Palliat Med 2009;12:215-17.

28. Emanuel EJ, Fairclough DL, Wolfe P, et al. Talking with terminally ill patients and their caregivers about death, dying and bereavement: is it stressful? Is it helpful? Arch Intern Med 2004:164:1999-2004.
906

907

908

909 